\title{
Acute kidney injury in cancer patients
}

\author{
Bruno Nogueira César ${ }^{7}$ \\ Marcelino de Souza Durão Júnior ${ }^{12}$
}

1. Disciplina de Nefrologia, Universidade Federal de São Paulo, São Paulo, SP, Brasil 2. Unidade de Transplante Renal Hospital Israelita Albert Einstein, São Paulo, SP, Brasil

\section{SUMMARY}

The increasing prevalence of neoplasias is associated with new clinical challenges, one of which is acute kidney injury (AKI). In addition to possibly constituting a clinical emergency, kidney failure significantly interferes with the choice and continuation of antineoplastic therapy, with prognostic implications in cancer patients. Some types of neoplasia are more susceptible to AKI, such as multiple myeloma and renal carcinoma. In cancer patients, AKI can be divided into pre-renal, renal (intrinsic), and post-renal. Conventional platinum-based chemotherapy and new targeted therapy agents against cancer are examples of drugs that cause an intrinsic renal lesion in this group of patients. This topic is of great importance to the daily practice of nephrologists and even constitutes a subspecialty in the field, the onco-nephrology.

KEYWORDS: Acute Kidney Injury. Neoplasia. Malignant tumor. Chemotherapy.

\section{INTRODUCTION}

With the epidemiological transition of recent decades, cancer has become the object of several clinical studies that resulted in more options for the diagnosis and treatment of the disease. Thus, there was an increase in the survival of patients, and handling complications of the disease and treatment adverse effects also became more common'.

The association between cancer and kidney disease has been known for a long time ${ }^{2,3}$. The kidney toxicity of antineoplastic drugs, renal lesions in multiple myelomas (MM), malignant obstructive uropathy, and oncologic emergencies, such as tumor lysis syndrome (TLS), are examples of renal diseases that affect cancer patients ${ }^{4}$. Acute kidney injury (AKI) increases the risk of toxic effects of chemotherapy
(CT), compromises the continuation of treatment, and limits the participation of patients in studies with new drugs.

\section{EPIDEMIOLOGY}

Among hospitalized patients, AKI is a common complication. Among those with cancer, the incidence reaches up to $12 \%$ of cases, and, often, the AKI develops within the first 48 hours of admission $^{5,6}$. A Danish study with 37,257 cancer patients had $17.5 \%$ of AKI incidence, per the definitions of the Rifle classification (Risk, Injury, Failure, Loss of kidney function, and End-stage kidney disease) ${ }^{7}$. In an environment of intensive therapy in cancer 
hospitals, the incidence increases to approximately up to $50 \%{ }^{4}$.

\section{CANCERS WITH A HIGHER RISK OF AKI}

The risk of AKI is greater in hematological neoplasias, especially in MM and neoplasms of the urinary tract, with emphasis on renal and bladder carcinomas $^{4,7,8}$. In cases of renal carcinoma treated with radical nephrectomy, $34 \%$ presented AKI, that this procedure was also a predictor of the development of chronic kidney disease (CKD) ${ }^{9}$. Among other hematological neoplasias, in a cohort of 537 patients with acute myeloid leukemia (AML) and high-grade myelodysplastic syndrome, 36\% developed $\mathrm{AKI}^{10}$.

\section{Risk factors}

In addition to certain types of cancer being more prone to renal injury, there are factors that increase that risk, among them: age (>65 years), female gender, chronic kidney disease, diabetes, hypertension, renal artery stenosis, advanced-stage cancer, hypoalbuminemia, hyponatremia, leukopenia, absolute (vomiting, diarrhea) or relative (congestive heart failure, cirrhosis or nephrotic syndrome) hypovolemia, use of contrast agents, chemotherapy, antibiotics, mechanical ventilation, vasoactive drugs, use of oral drugs - diuretics, non-steroidal anti-inflammatory drugs (NSAIDs), angiotensin-II-converting enzyme inhibitors II (ACEI) or angiotensin II receptor block$\operatorname{ers}(\mathrm{ARB})^{6,8,10-12}$.

\section{Evaluation of renal function in cancer patients}

Equations that estimate the glomerular filtration rate (GFR) as those of the MDRD (Modification of Diet in Renal Disease) and CKD-EPI (Chronic Kidney Dis- ease Epidemiology Collaboration) studies use as reference the iothalamate clearance and are currently the bedside methods available that offer the best accuracy and convenience for the evaluation of renal function. The Cockcroft Gault (CG) equation, since it is based on the creatinine clearance, may underestimate the glomerular filtration rate in elderly and malnourished patients, common characteristics among cancer patients. However, it is still used because it was the method chosen by the FDA (Food and Drug Administration) in 1998 as the standard for dose correction in patients with kidney failure and cancer ${ }^{13}$.

Cancer patients often present alterations in the GFR that are not detected by the physician. In a multicenter study with 4,684 patients, the use of creatinine alone underestimated the diagnosis of CKD, since $60 \%$ of patients with GFR estimated at $<90 \mathrm{ml} /$ $\min / 1.73 \mathrm{~m}^{2}$ had creatinine values within the limits of normality ${ }^{14}$. Therefore, the search for more accurate biomarkers is the target of research. That is the case of cystatin C, produced in constant concentrations by all nucleated cells and freely filtered at the glomerulus, is not relevantly influenced by the nutritional state and muscle mass, which makes its use promising, although there have been contradictory preliminary studies estimating the GFR in cancer patients ${ }^{15}$.

Regarding the definition of renal injury in these patients, most clinical studies published used the 2004 Rifle criteria. In 2012, the Kdigo (Kidney Disease Improve Global Outcomes) classification established a new system for defining and classifying acute kidney injury (Table 1). For the calculation, it is necessary to know the value of the baseline creatinine, which is the value reviewed from the last 7 to 365 days prior to hospital admis-

TABLE 1. CRITERIA FOR ACUTE KIDNEY INJURY

\begin{tabular}{|c|c|c|c|c|c|}
\hline \multicolumn{4}{|c|}{ RIFLE* 2004} & AKIN 2007 & \multirow[t]{2}{*}{ KDIGO 2012} \\
\hline $\begin{array}{l}\text { Criteria } \\
\text { Stages }\end{array}$ & $\begin{array}{l}\text { Diuresis } \\
\text { (Same criteria in all } \\
\text { three classifications) }\end{array}$ & $\begin{array}{l}\text { GFR } \\
\text { (Estimated } \\
\text { decrease) }\end{array}$ & \multicolumn{2}{|l|}{ Creatinine clearance } & \\
\hline 1 & $<0.5 \mathrm{ml} / \mathrm{kg} / \mathrm{h}$ in $6 \mathrm{~h}$ & $>25 \%$ & Risk: $\geq 1.5 \times C r(s)$ & $\begin{array}{l}\geq 1.5 x \\
\text { or increase } \geq 0.3 \mathrm{mg} / \mathrm{dl}\end{array}$ & $\begin{array}{l}\geq 1.5 x \text { or } \\
\text { increase } \geq 0.3 \mathrm{mg} / \mathrm{dl}\end{array}$ \\
\hline 2 & $<0.5 \mathrm{ml} / \mathrm{kg} / \mathrm{h}$ in $12 \mathrm{~h}$ & $>50 \%$ & Injury: $\geq 2 \times \mathrm{Cr}(\mathrm{s})$ & $\geq 2 x$ & $\geq 2 x$ \\
\hline 3 & $\begin{array}{l}<0.3 \mathrm{ml} / \mathrm{kg} / \mathrm{h} \text { in } 24 \mathrm{~h} \\
\text { or anuria for } 12 \mathrm{~h}\end{array}$ & $>75 \%$ & Failure: $\geq 3 \times \mathrm{Cr}(\mathrm{s})$ & $\begin{array}{l}\geq 3 x \text { or } \geq 4 \mathrm{mg} / \mathrm{dl}+\text { increase of } \\
\geq 0.5 \mathrm{mg} / \mathrm{dl} \text { or } \mathrm{TRS}\end{array}$ & $\begin{array}{l}\geq 3 x \text { or increased to values } \geq \\
4 \mathrm{mg} / \mathrm{dl}^{\star \star} \text { or RRT }\end{array}$ \\
\hline Time & In hours & \multicolumn{2}{|c|}{ In the last 7 days } & in $48 h$ & $\begin{array}{l}\geq 1.5 \mathrm{x} \text { in up to } 7 \text { days } \\
\geq 0.3 \mathrm{mg} / \mathrm{dl} \text { in } 48 \mathrm{~h}\end{array}$ \\
\hline
\end{tabular}


sion; or the lowest value recorded during hospitalization. When the baseline value is unknown, the calculation of the creatinine value corresponds to the GFR estimated by a MDRD of $75 \mathrm{ml} / \mathrm{min} / 1.73$ $\mathrm{m}^{2}$. However, in patients with previous CKD, this type of calculation may overestimate the incidence of AKI and its severity ${ }^{16}$.

New biomarkers of acute kidney injury are under study, among which those related to inflammation are especially noteworthy, such as neutrophil gelatinase-associated lipocalin (NGAL) and those involved in cell cycle, like the tissue inhibitors of metalloproteinases (TIMP-2) and the IGF binding proteins (IGFBP-7), which require further studies involving cancer patients ${ }^{17}$.

\section{CAUSES OF AKI IN CANCER PATIENTS}

In a cohort study, the most frequent causes of AKI were ischemia/shock, sepsis, contrast/nephrotoxins, obstruction, post-nephrectomy (renal carcinoma), and $\mathrm{TLS}^{18}$. In another study with hematological cancer patients, $68.5 \%$ presented AKI, and the main causes were hypoperfusion, TLS, acute tubular necrosis, and nephrotoxic agents ${ }^{19}$. In addition to the etiologies that are common among the general population (sepsis, NSAIDs, antibiotics, and contrast), cancer patients have a higher incidence of injuries due to antineoplastic drugs, post-renal injuries (genitourinary tumors), paraneoplastic syndromes, and TLS after chemotherapy.

In a systematic approach, we can separate the AKI etiologies associated with pre-renal, renal (intrinsic), and post-renal cancer, as is already done in the general population (Tables 2, 3, and 4).

\section{Pre-renal}

It is the most common cause of acute kidney injury in this group. The low oral intake, vomiting, and diarrhea after chemotherapy are responsible for most of the cases ${ }^{20}$. Fluid loss can also occur due to diabetes insipidus (DI) (nephrogenic - due to hypercalcemia, chemotherapic, post-renal - or central due to brain injury), third spacing, formation of cavitary effusion, and insensible losses (febrile neutropenia).

\section{Post-renal}

Cases of post-renal lesions are more common in cancer patients than in the general population ${ }^{21}$. The tumors were most frequently involved are those of

\section{TABLE 2. CAUSES OF PRE-RENAL LESION IN CANCER}

\begin{tabular}{l} 
Absolute hypovolemia \\
\hline Low food intake, vomiting, diarrhea \\
- Gastrointestinal effects of chemotherapy \\
- Obstructive abdomen (primary tumors or distant metastasis, \\
adherence due to surgery/previous radiotherapy) \\
- Injuries of the gastrointestinal mucosa of graft-versus-host \\
disease \\
Polyuria \\
- Diabetes insipidus \\
Insensible Losses \\
- Sepsis/febrile neutropenia \\
Others \\
- Losses due to ostomies and drains \\
Relative hypovolemia \\
Vasodilation/hypotension. \\
- Sepsis \\
- Veno-occlusive disease/ Hepatorenal syndrome \\
- latrogenic (antihypertensives) \\
Renal vasoconstriction \\
- Drugs (NSAIDS, calcineurin inhibitors) \\
Decreased cardiac output \\
- Heart failure due to coronary disease or cardiotoxic drugs \\
Third Spacing \\
- Metastases implants and cavitary effusion \\
- Hypoalbuminemia/ nephrotic syndrome \\
Vascular compression \\
\hline - Intra-abdominal hypertension/ abdominal compartment syn- \\
drome \\
\hline
\end{tabular}

the urinary tract, such as of the prostate and bladder, and those the adjacent systems, such as gynecological and gastrointestinal, and previous local therapeutic interventions such as surgery and radiotherapy increase the risk. This lesion may become irreversible; thus, prompt intervention is necessary. Before definitive surgery, maneuvers to decompress the urinary tract can be used, with ureteral catheters or nephrostomy. The decision on the use of decompression can be based on the presence of clinical parameters that compromise survival, such as hypoalbuminemia, degree of hydronephrosis, and metastatic events ${ }^{22}$. After reducing the obstruction, the tubular cells can be insensitive to vasopressin (nephrogenic DI), with possible polyuria and loss of electrolytes. Thus, it is of fundamental importance to control the hydroelectrolytic balance ${ }^{23}$.

Although infrequent, anuria, flank pain, and a palpable mass are the clinical triad of post-renal AKI. Other possible signs are hematuria, abdominal distension, vesical dysfunction, and urinary tract infection. Urinary sediment is usually harmless and may contain red blood cells, crystals (uric acid), and cylinders (light chains). In addition to DI, hyperchloremic acidosis with hyperkalemia is suggestive of type IV 
renal tubular acidosis ${ }^{12}$. The definitive diagnosis of post-renal AKI is confirmed by radiological examination. Kidney ultrasonography (USG) is an excellent tool for the rapid detection of hydronephrosis/hydroureter. Occasionally, the findings may be negative, if the obstruction is of short duration or when there is renal entrapment due to cancer/retroperitoneal fibrosis. Computed tomography or magnetic resonance imaging are examinations that give more details on the obstruction, guiding the appropriate treatment.

In addition to tumors that compress the urinary tract, intraluminal causes should also be remembered, such as intratubular cylinders (light chain myeloma) and ureterolithiasis (Table 3).

\section{TABLE 3. CAUSES OF POST-RENAL LESIONS}

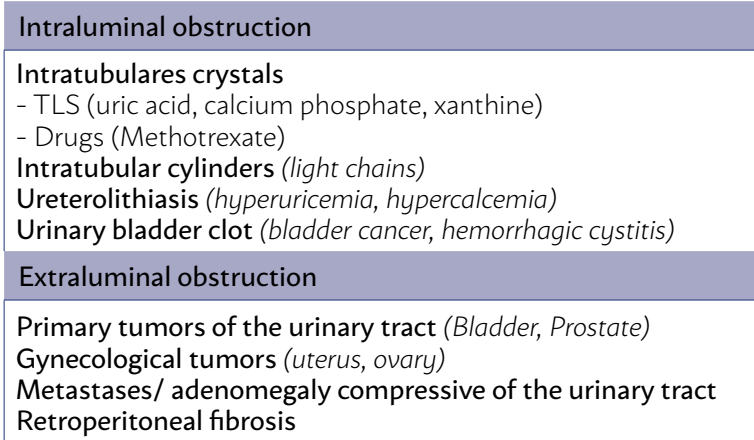

\section{Renal (intrinsic)}

Acute tubular necrosis due to sepsis and nephrotoxic agents such as antibiotics and contrast are important intrinsic etiologies in this group of patients. However, other causes specific of cancer patients should be remembered, among them nephrotoxicity caused by chemotherapy, TLS, renal injury related to MM, and renal carcinoma (post-nephrectomy).

\section{TABLE 4. INTRINSIC RENAL INJURY}

Sepsis
Nephrotoxic drugs
- Chemotherapy drugs, targeted therapy against cancer, immuno-
therapy
- Bisphosphonates
- Antibiotics, antivirals
Contrast
Ischemia/ pre-renal progression
Tumor lysis syndrome
Paraproteinemias
Infections (pyelonephritis, viral infection - BK and Adenovirus)
Renal carcinoma (post-nephrectomy)
Tumor infiltration (lymphoma and leukemia)
Glomerulopathies
- Membranous, thrombotic microangiopathies, amyloidosis and
others
Endogenous nephrotoxins
- Hyperuricosuria, hemoglobinuria, and myoglobinuria

\section{Antineoplastic drugs}

Table 5 shows the classes of drugs most frequently involved with nephrotoxicity in daily practice.

Platinum-based drugs are the most frequently involved in cases of nephrotoxicity. The class prototype is the cis-diamminedichloroplatinum (II) (CDDP) or cisplatin. This drug is commonly used in tumors of the lung, head and neck, bladder, testicles, and ova$\mathrm{ry}^{24}$. Acute kidney injury occurs in approximately onethird of the patients. The drug affects several renal compartments and presents clinical manifestations, from renal injury to thrombotic microangiopathy and tubulopathies, with various electrolyte disturbances during its course, among them hypomagnesemia, proximal tubulopathy, and nephrogenic $\mathrm{DI}^{25}$. Renal injury can be prevented by adjusting the dose and maintaining adequate hydration; some studies showed benefits with the use of amifostine (free radical binder) and with a magnesium infusion during preparation for $\mathrm{CT}^{26,27}$. Analog substances, such as carboplatin and oxaliplatin, seem to be less nephrotoxic.

The ifosfamide is an alkylating agent used in the treatment of sarcomas, lymphomas, and testicle tumors. It is also associated with increased tubular injury and can manifest in the form of Fanconi Syndrome and even nephrogenic DI. The drug metabolite, chloroacetaldehyde, is the great responsible for the injury. In cyclophosphamide, another drug of the same class, this compound is formed in smaller quantities, and acrolein is produced, whose main side effect is hemorrhagic cystitis. The Mesna synthetic compound binds to and prevents cystitis ${ }^{24}$.

The evolution of research in therapeutic tools to fight cancer has led to the emergence of drugs that act more directly on the tumor and have a lower effect against other cells. Among these are the target agents against cancer. The vascular endothelial growth factor (VEGF) and its receptor (VEGFR) and tyrosine kinase inhibitors - who act against the VEGFR and also against the platelet-derived growth factor receptor (PDGFR) - are some of the examples of targets of this new class of drugs, which ends up acting in the tumoral angiogenesis. The VEGF and its receptor are also present in podocytes, the endothelium, mesangium, and kidney tubular cells ${ }^{28}$. Thus, the glomerular lesions most frequently observed are endotheliosis, focal and segmental glomerulosclerosis, and thrombotic microangiopathy. Thus, patients who use these drugs commonly develop hypertension (which is actually a marker 
TABLE 5. EXAMPLES OF ANTINEOPLASTIC DRUGS RELATED TO RENAL LESION

\begin{tabular}{|l|l|}
\hline Antineoplastic drugs & Examples \\
\hline Conventional chemotherapy agents \\
\hline $\begin{array}{l}\text { Platinum-based } \\
\text { Alkylating } \\
\text { Antimetabolites }\end{array}$ & $\begin{array}{l}\text { Cisplatin, carboplatin, oxaliplatin } \\
\text { Ifosfamide, cyclophosphamide } \\
\text { Methotrexate, gemcitabine }\end{array}$ \\
\hline Targeted therapy & \\
\hline $\begin{array}{l}\text { Anti-VEGF antibodies } \\
\text { Tyrosine kinase inhibitors } \\
\text { EGFR inhibitors } \\
\text { Checkpoint inhibitors } \\
\text { - Anti-PD1 antibodies } \\
\text { - Anti-CTL-4 antibodies } \\
\text { mTOR }\end{array}$ & Bevacizumab, Aflibercept \\
\hline Onatinib, Pazopanib, Sorafenib, \\
\hline Others & Cetuximab, Panitumumab \\
IL2, IFN, Bisphosphonates, Denosumab, Nivolumab \\
\hline
\end{tabular}

of adequate antitumor response) and mild proteinuria. They can also develop nephrotic syndrome, AKI, and thrombotic microangiopathy, which should be monitored. Proteinuria should be treated with ACEI/ARB, and hypertension with the same drugs or dihydropyridine calcium channel blockers, such as nifedipine. Acute kidney injury with thrombotic microangiopathy is an indication to suspend the antineoplastic drug ${ }^{28,29}$.

\section{CONCLUSION}

In addition to the etiologies briefly explored in this review, it is worth stressing the importance of acute kidney injury related to the transplantation of hematopoietic cells and renal carcinoma. The emergence of the onco-nephrology subspecialty caters to the need to integrate the treatment of patients with cancer and renal dysfunction. Interaction with other specialties is mandatory: oncology, hematology, urology, clinical pharmacy, a multi-professional team, and others.

\section{Contribution of the authors:}

Bruno Nogueira César ${ }^{1}$, literature review, drafting of the paper. Marcelino de Souza Durão Júnior ${ }^{12}$, literature review, drafting, and review of the article.

\section{RESUMO}

A crescente prevalência de neoplasias se associa a novos desafios clínicos, sendo a lesão renal aguda (LRA) um deles. Além de ser possivel emergência clínica, a insuficiência renal interfere significativamente na escolha e continuação da terapia antineoplásica, tendo implicações prognósticas no paciente com câncer. Alguns tipos de neoplasias são mais suscetíveis a LRA, como o mieloma múltiplo e o carcinoma renal. Nos pacientes oncológicos, a LRA pode ser dividida em pré-renal, renal (intrínseca) e pós-renal. A quimioterapia convencional com platinas e os novos agentes de terapia-alvo contra o câncer são exemplos de drogas que causam lesão renal intrínseca nesse grupo de pacientes. Este tema é de grande importância atual para a prática diária do nefrologista, tornando-se inclusive subespecialidade na área, a onconefrologia.

PALAVRAS-CHAVE: Lesão renal aguda. Neoplasia. Tumor maligno. Quimioterapia.

\section{REFERENCES}

1. Cohen EP, Krzesinski JM, Launay-Vacher V, Sprangers B. Onco-nephrology: Core Curriculum 2015. Am J Kidney Dis. 2015;66(5):869-83.

2. Humphreys BD. Onco-nephrology: kidney disease in the cancer patient: introduction. Semin Nephrol. 2010;30(6):531-3.

3. Berns JS, Rosner MH. Onco-nephrology: what the nephrologist needs to know about cancer and the kidney. Clin J Am Soc Nephrol. 2012;7(10):1691.

4. Liborio AB, Abreu KL, Silva GB, Jr., Lima RS, Barreto AG, Barbosa OA, et al. Predicting hospital mortality in critically ill cancer patients according to acute kidney injury severity. Oncology. 2011;80(3-4):160-6.

5. Moore PK, Hsu RK, Liu KD. Management of Acute Kidney Injury: Core Curriculum 2018. Am J Kidney Dis. 2018;72(1):136-48.

6. Salahudeen AK, Doshi SM, Pawar T, Nowshad G, Lahoti A, Shah P. Incidence rate, clinical correlates, and outcomes of $\mathrm{AKI}$ in patients admitted to a comprehensive cancer center. Clin J Am Soc Nephrol. 2013;8(3):347-54.

7. Christiansen CF, Johansen MB, Langeberg WJ, Fryzek JP, Sorensen HT. Incidence of acute kidney injury in cancer patients: a Danish population-based cohort study. Eur | Intern Med. 2011;22(4):399-406.

8. Kitchlu A, McArthur E, Amir E, Booth CM, Sutradhar R, Majeed H, et al. Acute Kidney Injury in Patients Receiving Systemic Treatment for Cancer: A Population-Based Cohort Study. J Natl Cancer Inst. 2018.
9. Cho A, Lee JE, Kwon GY, Huh W, Lee HM, Kim YG, et al. Post-operative acute kidney injury in patients with renal cell carcinoma is a potent risk factor for new-onset chronic kidney disease after radical nephrectomy. Nephrol Dial Transplant. 2011;26(11):3496-501

10. Lahoti A, Kantarjian H, Salahudeen AK, Ravandi F, Cortes JE, Faderl S, et al. Predictors and outcome of acute kidney injury in patients with acute myelogenous leukemia or high-risk myelodysplastic syndrome. Cancer. 2010;116(17):4063-8.

11. Perazella MA. Renal vulnerability to drug toxicity. Clin | Am Soc Nephrol. 2009;4(7):1275-83.

12. Campbell GA, Hu D, Okusa MD. Acute kidney injury in the cancer patient. Adv Chronic Kidney Dis. 2014;21(1):64-71.

13. Casal MA, Nolin TD, Beumer JH. Estimation of Kidney Function in Oncology: Implications for Anticancer Drug Selection and Dosing. Clin J Am Soc Nephrol. 2019;14(4):587-95.

14. Launay-Vacher V, Oudard S, Janus N, Gligorov J, Pourrat X, Rixe O, et al. Prevalence of Renal Insufficiency in cancer patients and implications for anticancer drug management: the renal insufficiency and anticancer medications (IRMA) study. Cancer. 2007;110(6):1376-84. 
15. Jones M, Denieffe S, Griffin C, Tinago W, Fitzgibbon MC. Evaluation of cystatin $C$ in malignancy and comparability of estimates of GFR in oncology patients. Pract Lab Med. 2017;8:95-104.

16. Gaiao S, Cruz DN. Baseline creatinine to define acute kidney injury: is there any consensus? Nephrol Dial Transplant. 2010;25(12):3812-4.

17. Lameire $N$, Vanholder R, Van Biesen W, Benoit D. Acute kidney injury in critically ill cancer patients: an update. Crit Care. 2016;20(1):209.

18. Soares M, Salluh II, Carvalho MS, Darmon M, Rocco IR, Spector N. Prognosis of critically ill patients with cancer and acute renal dysfunction. J Clin Oncol. 2006;24(24):4003-10.

19. Canet E, Zafrani L, Lambert J, Thieblemont C, Galicier L, Schnell D, et al Acute kidney injury in patients with newly diagnosed high-grade hematological malignancies: impact on remission and survival. PLoS One. 2013;8(2):e55870.

20. Berk L, Rana S. Hypovolemia and dehydration in the oncology patient. Support Oncol. 2006;4(9):447-54; discussion 55-7.

21. Humphreys BD, Soiffer RJ, Magee CC. Renal failure associated with cancer and its treatment: an update. J Am Soc Nephrol. 2005;16(1):151-61.
22. Ishioka J, Kageyama Y, Inoue M, Higashi Y, Kihara K. Prognostic model for predicting survival after palliative urinary diversion for ureteral obstruction: analysis of 140 cases. J Urol. 2008;180(2):618-21; discussion 21.

23. Atamer T, Artim-Esen B, Yavuz S, Ecder T. Massive post-obstructive diuresis in a patient with Burkitt's lymphoma. Nephrol Dial Transplant. 2005;20(9):1991-3.

24. Perazella MA. Onco-nephrology: renal toxicities of chemotherapeutic agents. Clin J Am Soc Nephrol. 2012;7(10):1713-21.

25. Liamis G, Filippatos TD, Elisaf MS. Electrolyte disorders associated with the use of anticancer drugs. Eur J Pharmacol. 2016;777:78-87.

26. Kidera Y, Kawakami H, Sakiyama T, Okamoto K, Tanaka K, Takeda M, et al. Risk factors for cisplatin-induced nephrotoxicity and potential of magnesium supplementation for renal protection. PLoS One. 2014;9(7):e101902.

27. Pabla N, Dong Z. Cisplatin nephrotoxicity: mechanisms and renoprotective strategies. Kidney Int. 2008;73(9):994-1007.

28. Porta C, Cosmai L, Gallieni M, Pedrazzoli P, Malberti F. Renal effects of targeted anticancer therapies. Nat Rev Nephrol. 2015;11(6):354-70.

29. Perazella MA, Izzedine H. New drug toxicities in the onco-nephrology world. Kidney Int. 2015;87(5):909-17. 